\title{
IMPLEMENTATION OF INTELLIGENT TRAFFIC MANAGEMENT SYSTEM USING IOT
}

\author{
Bhavana Ganga R \\ M.Tech, Student, Department of TCE, \\ R V College of Engineering, Banagalore, India \\ Dr. K. Nagamani \\ Professor, Department of TCE, \\ R V College of Engineering, Banagalore, India
}

\begin{abstract}
Road traffic congestion is the major issue in metropolitan cities like Delhi, Mumbai, Bangalore, Chennai, Hyderabad etc. Also, increasing population leads to increasing vehicles on road. Traffic signal jumps by other vehicles have become common in recent days. Sometimes cause road accidents. Therefore, there is a need of automated system to control traffic signal and give way to ambulance to reach destination. Internet of Things technology gives solution to have smart and intelligent traffic management system. Traffic signal operates in normal mode in the absence of ambulance service. In the presence of ambulance near the traffic signal lights, traffic signal lights turn green to give way to the ambulance service. RFID reader reads the RFID tag and update to cloud service ThingSpeak application. Meanwhile, microcontroller instructs to the traffic light signal to turn green and servo motor with barricade system to turn open. Ambulance service passes that traffic light signal. Traffic light signals shift to normal mode operation. Every traffic signal light operates in similar way to give way to clearance for ambulance service so that ambulance service reaches the destination without any delay and in time.
\end{abstract}

Key words: Traffic signal light, Arduino Mega, ESP8266, Ambulance, Arduino IDE, ThingSpeak.

Cite this Article: Bhavana Ganga $\mathrm{R}$ and Dr. K. Nagamani, Implementation of Intelligent Traffic Management System using IoT. International Journal of Electrical Engineering and Technology, 11(5), 2020, pp. 22-30.

http://iaeme.com/Home/issue/IJEET?Volume $=11 \&$ Issue $=5$

\section{INTRODUCTION}

IoT concept can be applied to any area. It can have smart transport system. IoT system can provide solution to ambulance stuck in road traffic jams. Increasing population tops to increase in number of vehicles on road. Hence, ambulance services become major problem to reach destination during such time. Ambulance gets stuck in road traffic jams. Ambulance 
can't reach the destination in time and cause delay. Road traffic congestion is monitored by manual ways. Traffic clearance is done by traffic police. Traffic police fails to control traffic. It becomes worse when traffic jams reach peak during peak hours. This situation makes emergency vehicles delay and cause patients death. One more problem is that traffic signal jump by other vehicles. Survey says that $95 \%$ heart attack patients life can be saved when emergency vehicle reach hospital in time. Ambulance service stuck in road traffic jams is as shown in figure 1. Need an automated system to clear the traffic jams and give way to ambulance service to reach hospital in time without causing delay. Intelligent and smart system makes the traffic signal lights to give way for ambulance service to reach hospital within time. Hence, save the life of patients.

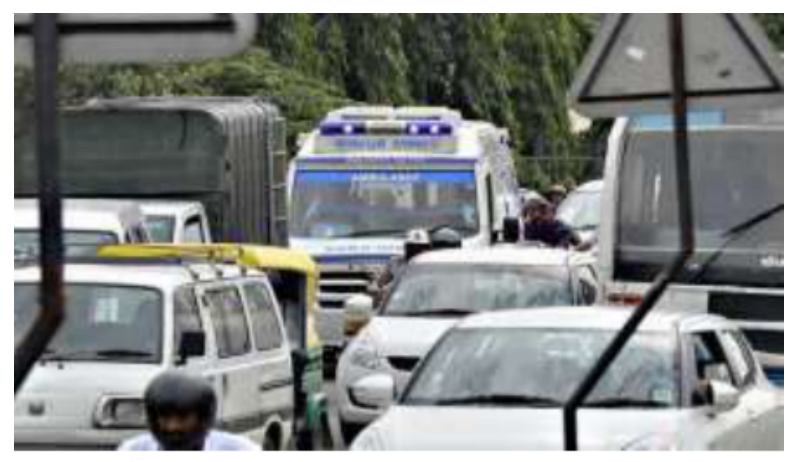

Figure 1 Ambulance service stuck in road traffic

Proposed project helps to alter the traffic signals for road clearance when ambulance service reaching the signal. Ambulance service is attached with RFID tag. Every traffic signal light has RFID reader at some prior distance. RFID reader is placed prior to some meters from the traffic signal light. Traffic signal light operates in normal mode when ambulance service is not around that traffic signal pole. Microcontroller controls all the components attached to it. It is the central processing and controlling unit of the proposed project. RFID reader emits electromagnetic waves around it. RFID reader reads RFID tag of ambulance and updates that ambulance is detected at that traffic signal junction. RFID reader updates to cloud service. Cloud service stores the data. Meanwhile, traffic signal light is made green to give clearance for ambulance service. Microcontroller coordinates all the function of the proposed project. Traffic signal light turns green and barricade opens to give green corridor for the ambulance to pass that signal and also to hospital in time without causing delay. Ambulance passes that signal and then traffic signal light shift to normal mode. Every traffic signal operates in similar way. Every data get stored in cloud service. Hence, emergency vehicle reaches the hospital without causing delay to destination. Patient's life is saved. Therefore, proposed project is life savior and intelligent to control traffic light signal to give clearance to emergency vehicle. Hence save time.

\section{BACKGROUND SURVEY}

\section{Present Traffic Signal System}

Road traffic clearance during emergency condition is done by manual methods. Manual method is time consuming and cause errors in the system. Traffic jam clearance in the metropolitan cities like Delhi, Mumbai, Bangalore etc. are difficult. Also, traffic increases day-by-day due to increase in number of vehicles on road.

\section{Proposed Traffic Signal System}

Proposed project consists of two sections that are ambulance section and traffic signal section. RFID tag is attached with each ambulance service. Therefore, RFID tag and ambulance 
together form the ambulance section. RFID tag of ambulance is read by RFID reader of traffic signal section, whenever ambulance service is near to that of traffic signal pole. RFID reader updates cloud services. So that traffic signal is turned green. It also updates servo motors so that barricade is open for ambulance service. Ambulance section passes that traffic signal pole without any traffic congestion. In every traffic signal the same system is implemented. By this way ambulance service reaches the required place in time without causing much delay. Hence, patient's life can be saved. Ambulance section is simple in implementation as shown in figure 2.

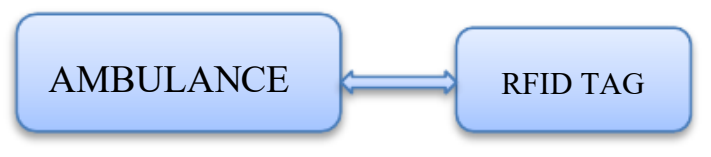

Figure 2 Ambulance section

Traffic signal section consists of Arduino Mega Microcontroller, ESP8266 Wi-Fi Module, two RFID Readers, LCD Display, two Red LED, two Yellow LED, two Green LED and two Servo Motors as shown in figure 3. In the proposed project, two traffic signal pole and two servo motors with barricade are present. Each traffic signal pole consists of red LED, yellow LED and green LED. Also, a servo motor with barricade. In the proposed project, two traffic signal poles and two servo motor with barricade is present. Also, two RFID readers are present. Each RFID reader is installed prior to some distance at traffic light pole. Controller used in the proposed project is Arduino Mega microcontroller. Traffic signal poles, servo motors with barricade and RFID reader are connected to Arduino Mega microcontroller. Processing of data takes place in Arduino Mega microcontroller. ESP8266 is connected to Arduino Mega. ESP266 helps to send data to cloud service. LCD helps to know the prominence of the proposed project which is connected to Arduino Mega.

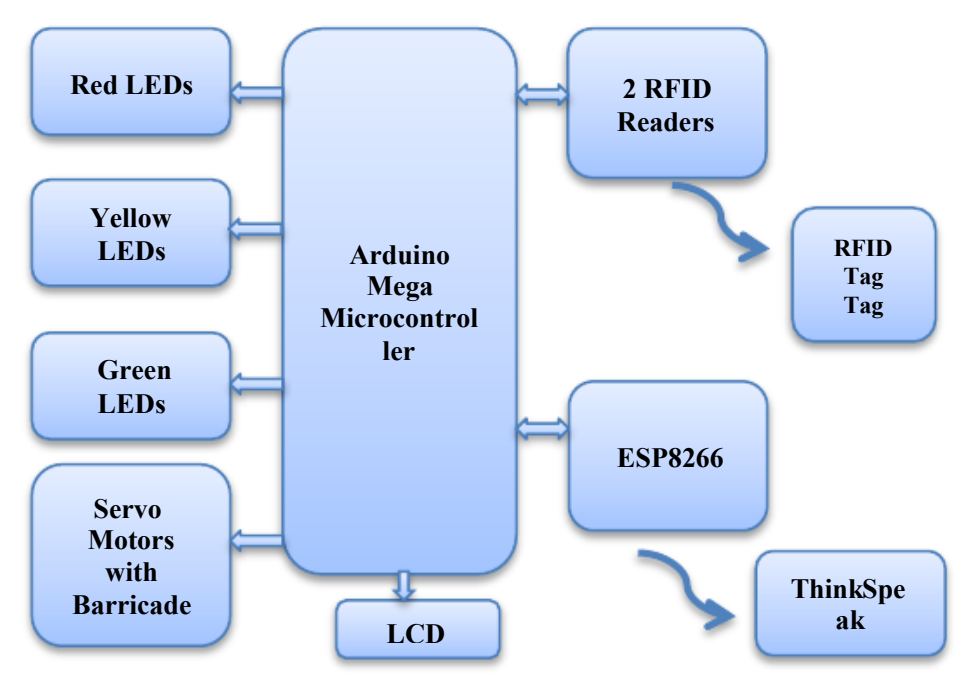

Figure 3 Traffic signal section

\section{DESIGN SPECIFICATIONS}

Design specification includes Arduino Mega microcontroller, ESP8266 Wi-Fi module, RFID, LCD, Servo motor with barricade, traffic signal LEDs, Arduino software IDE and ThingSpeak android application. 


\section{Arduino Mega 2560}

Arduino Mega 2560 has ATmega2560 mc in it. ATmega2560 is 8 bit mc. Arduino Mega 2560 contains components such has $16 \mathrm{MHz}$ oscillator, USB connection, four UART, 54 digital input/output pins and 16 analog inputs.

\section{ESP8266}

ESP8266 is system on chip (SoC) which provides Wi-Fi facility. It is developed by Espressif system. It provides applications in Internet of Things embedded system. ESP8266 can act as hotspot or it connects to Wi-Fi network. It has integrated with TCP/IP protocol. It supports $2.4 \mathrm{GHz}$.

\section{RFID Reader \& RFID Tag}

RFID is acronym of Radio Frequency Identification. In RFID technology digital data which is encrypted in RFID tags are identified by RFID tags through electromagnetic waves.

\section{LCD Display}

LCD has 16 columns and 2 rows. Therefore 32 characters can be displayed. Each character size is $5 \times 8$ pixel dots. It displays both numbers and alphabets.

\section{Servo Motor with Barricade}

Servo motor can push or rotate with specific distance or angles of any object. Servo motor consists of motor, controlling circuit, gear assembly and potentiometer.

\section{Traffic Signal LED}

Red, green and yellow LEDs are used. Size of each LED is $8 \mathrm{~mm}$. It requires $5 \mathrm{~V}$ power supply and is supplied by microcontroller.

\section{Arduino IDE}

Arduino IDE offers software background to Arduino based projects. The upside menu bar provides File, Edit, Sketch, Tools and Help options. Middle menu is for coding. The downside menu is to see output. Sketches use $\mathrm{C}++$ or $\mathrm{C}$ programming.

\section{ThingSpeak}

ThingSpeak is an open stage for IoT application or projects. It acts as cloud service. ThingSpeak provide API. API helps to transmit and receive data. HTTP and MQTT protocol is used for communication.

\section{IMPLEMENTATION}

In the proposed project, two roads are considered that named as road 1 and road 2. Prototype of the project is considered and implemented as shown in figure 4. In road 1, RFID reader 1, servo motor with barricade 1 and traffic light signal 1 are placed. In road 2, RFID reader 2, servo motor with barricade 2 and traffic light signal 2 are placed. Distance between RFID reader and traffic light signal pole is $20 \mathrm{~cm}$. In real implementation it can be placed meters apart. For the project prototype purpose it is placed centimeters apart. Both RFID readers are placed $20 \mathrm{cms}$ apart from the traffic light signal pole. 


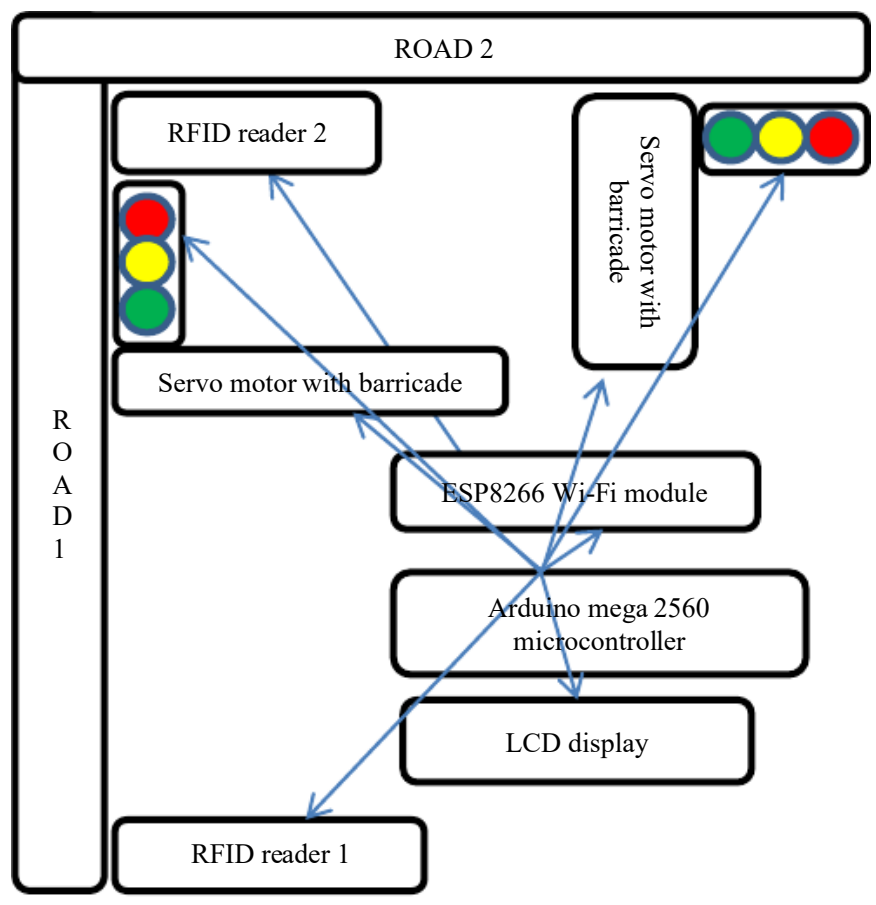

Figure 4 Implementation of proposed traffic management system

In the proposed project, two modes are created. They are regular operation and emergency operation. In the regular operation, ambulance service doesn't exist in road 1 and road 2. Traffic light LEDs red, yellow and green turn on and off for the fixed amount of time in road 1 and road 2.

In the emergency operation, ambulance service is detected either in road 1 or road 2 . If ambulance service is detected at road 1, road 2 will have normal mode operation or vice versa. RFID reader 1 of road 1 detects the RFID tag of ambulance service prior to traffic signal light 1 . As it is placed $20 \mathrm{~cm}$ prior to traffic signal light 1 . Meantime, RFID reader 1 sends the detected ambulance data to the cloud. Cloud service ESP8266 sends the information to the cloud. Meanwhile, traffic signal LEDs 1 and servo motor with barricade 1 is instructed to give clearance to ambulance. Arduino Mega 2560 micro controls all the action. Traffic signal LEDs 1 is made green and servo motor with barricade 1 is opened until the ambulance passes the road 1 traffic signal. Duration is pre fixed in Arduino IDE software. Similarly, same procedure is followed at road 2 if ambulance is detected by RFID reader 2 . In the ThingSpeak android application data is represented in the form of chart.

\section{EXPERIMENTAL RESULTS}

Prototype of the proposed project consists of two roads named as road 1 and road 2. Prototype is as shown in figure 5.

Normal operation of traffic light signal are turning ON red LED for 10 seconds, yellow LED for 5 seconds and green LED for 5 seconds. RFID reader reads RFID tag when it is near to it. RFID Reader produces a buzz sound and light when it reads RFID tag. RFID Reader 1 reading RFID tag as shown in figure 6 . Traffic signal light 1 turning green when RFID reader 1 reads RFID tag as shown in figure 7. Detection of ambulance with RFID tag is displayed in LCD display as shown in figure 8. Ambulance detection data is uploaded to ThingSpeak as shown in 9. ThingSpeak stores data in the form of graph. On the x-axis time and date is saved. On the y-axis road number is saved. If ambulance get detected in road 1, red dot is marked on road 1 of $y$-axis with time and date on $\mathrm{x}$-axis. If ambulance gets detected in road 2, red dot is marked on road 2 of $y$-axis with time and date on y-axis. Meantime, Traffic light signal is 
turned green for 5 seconds and servo motor with barricade is open so that ambulance gets green corridor. Once the ambulance gets passed traffic signal lights shift to normal operation. Similarly, ambulance detection on road 2 takes place.

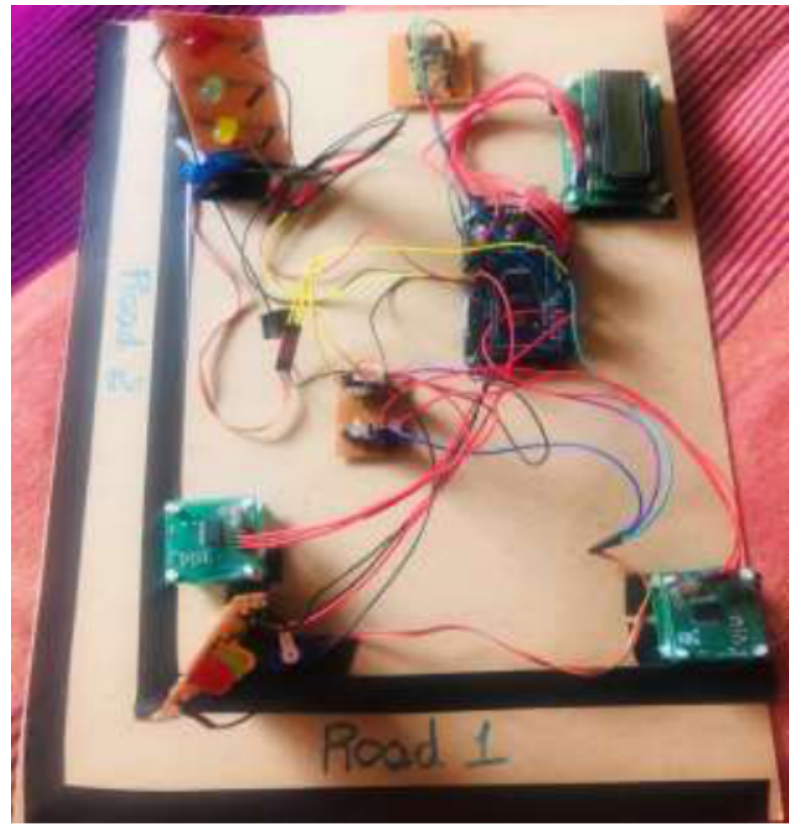

Figure 5 Prototype of the proposed project

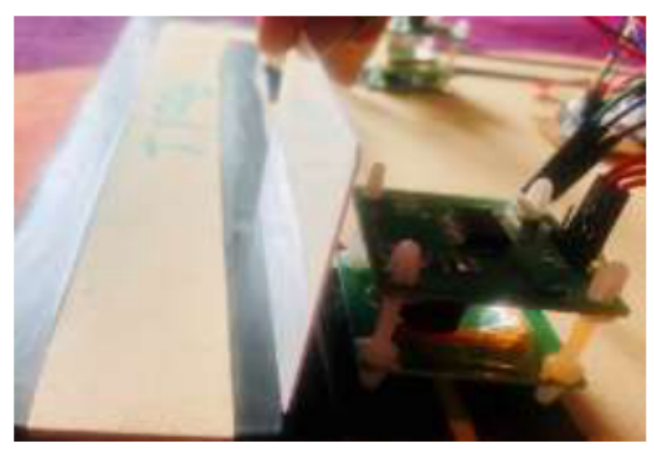

Figure 6 RFID reader 1 reading RFID tag on road 1

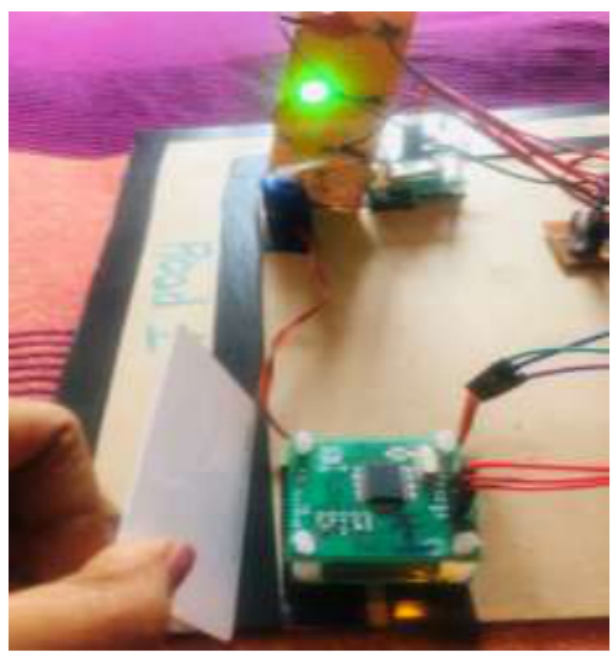

Figure 7 Ambulance detection, traffic signal turning green \& barricade open to provide green corridor on road 1 


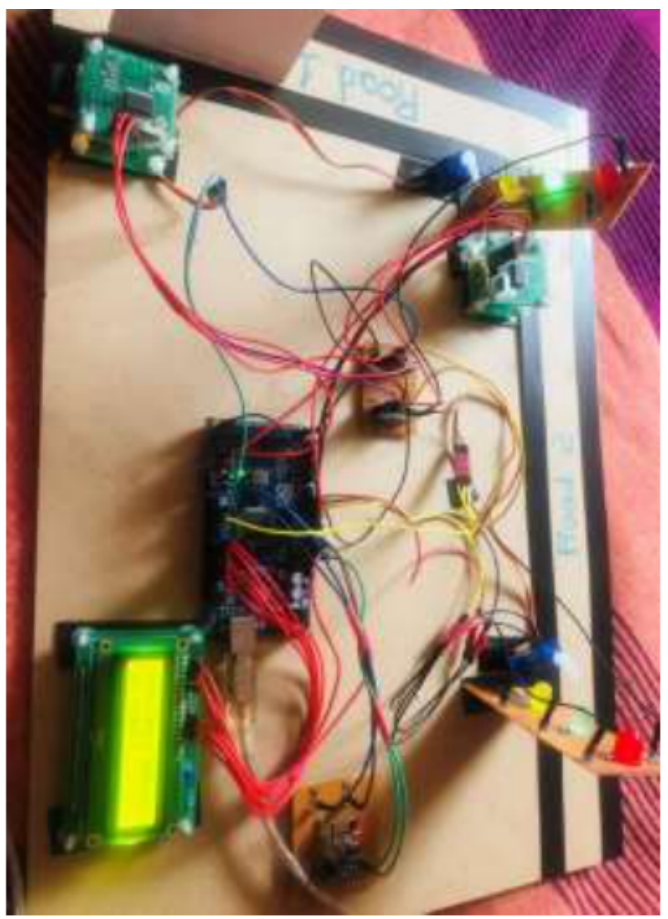

Figure 8 LCD display message of ambulance detection on Road 1

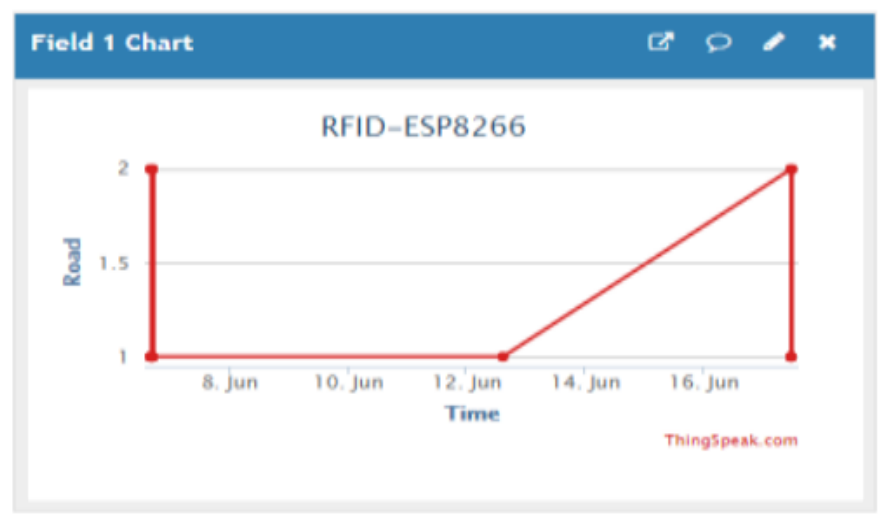

Figure 9 Last red dot represents ambulance detection on road 1

\section{CONCLUSION \& FUTURE SCOPE}

Ambulance service plays a very important role in saving human life during emergency conditions. Hence, proposed project is intelligent management of traffic signal using Internet of Thing concept to provide green corridor for ambulance service. Internet of Things makes the system smart and automated. It uses cloud service to store data and monitor the system. Radio Frequency Identification (RFID) is more efficient than other pressure sensors or also camera. RFID reader detects ambulance service quickly by reading RFID tag. Detected information is updated to cloud service within no time. ThingSpeak android application is easily downloadable and open source. Arduino Mega microcontroller performance is much better than any other microcontroller. Microcontroller coordinates all the functions and provide green corridor for ambulance for about fixed duration. Prototype of the proposed project is tested. RFID reader is placed $20 \mathrm{~cm}$ apart from traffic signal light. RFID tag of ambulance gets detected when it is $5 \mathrm{~cm}$ near to it. Within no time traffic signal is made green to provide space for ambulance service. Traffic signal maintains green for 5 seconds and shift to normal operation. Baud rate for RFID communication is 9600 baud ad baud rate for ESP 
$8266 \mathrm{Wi}-\mathrm{Fi}$ module is 115200 baud. Graph is viewed on ThingSpeak application. Graph signifies on which road ambulance service is traversed with the exact date and time. Therefore, proposed project saves the life of human beings during emergency by controlling traffic signal to turn green and providing way to ambulance service. Real time implementation is to be tested in future.

\section{ACKNOWLEDGMENT}

I would like to thank Dr. K. Nagamani, professor, department of Telecommunication Engineering, RVCE for the constant support and guidance.

\section{REFERENCES}

[1] B. J. Saradha, G. Vijayshri and T. Subha, "Intelligent traffic signal control system for ambulance using RFID and cloud," 2017 2nd International Conference on Computing and Communications Technologies (ICCCT), Chennai, 2017, pp. 90-96. doi: 10.1109/ICCCT2.2017.

[2] T. Chowdhury, S. Singh and S. M. Shaby, "A Rescue System of an advanced ambulance using prioritized traffic switching," 2015 International Conference on Innovations in Information, Embedded and Communication Systems (ICIIECS), Coimbatore, 2015, pp. 1-5. doi: 10.1109/ICIIECS.2015.

[3] Saurabh Kapoor, Parul Gupta, Pooja Sharma and Prabhu Nath Singh, "Intelligent Ambulance with Automatic Traffic Control, " 2017 International Research Journal of Engineering and Technology (IRJET), Utter Pradesh, 2017, pp. 1264 - 1266. doi: 5.181/IRJET.2017.

[4] V. Parthasarathi, M. Surya, B. Akshay, K. Murali Siva and Shriram K. Vasudevan, "Smart Control of Traffic Signal System using Image Processing," 2015 Indian Journal of Science and Technology, Coimbatore, 2015, pp. 1-5. doi: 10.17485/IJST.2015.

[5] B. Kapusta, M. MiletiC, E. Ivanjko and M. Vujić, "Preemptive traffic light control based on vehicle tracking and queue lengths," 2017 International Symposium ELMAR, Zadar, 2017, pp. 11-16. doi: 10.23919/ELMAR.2017.

[6] Y. Huang, S. Chen, F. Leu, C. Ko and J. Liu, "A Secure Traffic Control System with Emergency Handling for Ambulances," 2014 International Conference on Intelligent Networking and Collaborative Systems, Salerno, 2014, pp. 356-361.doi: 10.1109/INCoS.2014.

[7] A. C, M. Kumar and P. Kumar, "City traffic congestion control in Indian scenario using wireless sensors network," 2009 Fifth International Conference on Wireless Communication and Sensor Networks (WCSN), Allahabad, 2009, pp. 1-6. doi: 10.1109/WCSN.2009.

[8] Z. Yang, S. Lu and X. Liu, "Combined Traffic Signal Control and Route Guidance: Multiple User Class Traffic Assignment Model versus Discrete Choice Model," The Proceedings of the Multiconference on "Computational Engineering in Systems Applications", Beijing, 2006, pp. 1957-1964. doi: 10.1109/CESA.2006.

[9] Y. Zhang and W. Yan, "Research of Traffic Signal Light Intelligent Control System Based on Microcontroller," 2009 First International Workshop on Education Technology and Computer Science, Wuhan, Hubei, 2009, pp. 301-303. doi: 10.1109/ETCS.2009.

[10] Bo Liu and Hiroaki Mizuta, "Discussion of traffic signal effect on calculating link travel time and field test evaluation," 2008 8th International Conference on ITS Telecommunications, Phuket, 2008, pp. 112-115. doi: 10.1109/ITST.2008.

[11] N. Al-Ostath, F. Selityn, Z. Al-Roudhan and M. El-Abd, "Implementation of an emergency vehicle to traffic lights communication system," 2015 7th International Conference on New Technologies, Mobility and Security (NTMS), Paris, 2015, pp. 1-5, doi: 10.1109/NTMS.2015.7266494. 
[12] A. A. Krishna, B. A. Kartha and V. S. Nair, "Dynamic traffic light system for unhindered passing of high priority vehicles: Wireless implementation of dynamic traffic light systems using modular hardware," 2017 IEEE Global Humanitarian Technology Conference (GHTC), San Jose, CA, 2017, pp. 1-5, doi: 10.1109/GHTC.2017.8239237.

[13] D. Vishal, R. J. Reddy, B. Abhirami M. and T. K. Ramesh, "Real Time Traffic Control for Emergency Service Vehicles," 2017 IEEE International Conference on Computational Intelligence and Computing Research (ICCIC), Coimbatore, 2017, pp. 1-4, doi: 10.1109/ICCIC.2017.8524354.

[14] Sangeetha, K., P. Archana, Mohandass Ramya and P. T. Ramya. "Automatic Ambulance Rescue with Intelligent Traffic Light System.” IOSR Journal of Engineering 4 (2014): 53-57.

[15] B. S. Meghana, S. Kumari and T. P. Pushphavathi, "Comprehensive traffic management system: Real-time traffic data analysis using RFID," 2017 International conference of Electronics, Communication and Aerospace Technology (ICECA), Coimbatore, 2017, pp. 168 171, doi: 10.1109/ICECA.2017.8212787.

[16] Laxmi Khichadi, Siva Ganesh Kumar, Dr. Nagamani.K," Building a Cloud Solution for Energy Management using Raspberry Pi" $4^{\text {th }}$ International conference on Communication and Electronics systems(ICCES-2019) organized by PPG Institute of Technology, Coimbatore, 17$19^{\text {th }}$ July 2019.

[17] Qiang Li et al., "Secure UHF-RFID tag for vehicular traffic management system," 2017 IEEE International Conference on RFID (RFID), Phoenix, AZ, 2017, pp. 26-29, doi: 10.1109/RFID.2017.7945582.

[18] V. Cherniy, S. Bezshapkin, O. Sharovara, I. Vasyliev and O. Verenych, "Modern Approach to the Road Traffic Management in Cities of Ukraine: Case Study of Kyiv Municipal Company "Road Traffic Management Center"," 2020 IEEE European Technology and Engineering Management Summit (E-TEMS), Dortmund, Germany, 2020, pp. 1-6, doi: 10.1109/ETEMS46250.2020.9111757.

[19] A. Rao, A. Phadnis, A. Patil, T. Rajput and P. Futane, "Dynamic Traffic System Based on Real Time Detection of Traffic Congestion," 2018 Fourth International Conference on Computing Communication Control and Automation (ICCUBEA), Pune, India, 2018, pp. 1-5, doi: 10.1109/ICCUBEA.2018.8697838.

[20] D. Nallaperuma et al., "Online Incremental Machine Learning Platform for Big Data-Driven Smart Traffic Management," in IEEE Transactions on Intelligent Transportation Systems, vol. 20, no. 12, pp. 4679-4690, Dec. 2019, doi: 10.1109/TITS.2019.2924883. 